\title{
Racial and Ethnic Backgrounds of U.S. Randomized Controlled Trials in Obstetrics and Gynecology and Comparison to U.S. General Population: A Retrospective Review
}

\author{
YUZURU ANZAI ${ }^{1}$, Noel Cercizi² ${ }^{2}$ Yifei $\mathrm{Wu}^{2}$, Crystal Park ${ }^{2}$, Jasmine Gulati ${ }^{2}$, Seoho Lee ${ }^{2}$, \\ William McClelland ${ }^{1}$, Teresa Cheon ${ }^{1}$, Maria Benedetto-Anzai ${ }^{1}$, and Frank Chervenak $^{1}$ \\ ${ }^{1}$ Lenox Hill Hospital \\ ${ }^{2}$ University of Chicago College
}

February 19, 2021

\begin{abstract}
Objective: To determine if the racial and ethnic compositions of the participants in Obstetrics and Gynecology randomized controlled trials (RCTs) conducted in the U.S. match that of the general U.S. population. Design: Retrospective analysis of U.S. RCTs. Setting: United States. Population: Women enrolled in U.S. RCTs. Methods: Racial and ethnic composition of RCT participants published in two premier US journals, Obstetrics and Gynecology and American Journal of Obstetrics and Gynecology, from January 2010 to April 2020 were collected and analyzed. Main outcome measures: Comparison of the racial and ethnic composition of the U.S. RCTs to U.S. General population. Results: Chi-square analysis showed significant deviations from the U.S. general population in both Obstetrics $(\mathrm{p}<0.001)$ and Gynecology $(\mathrm{p}<0.05)$. We observed an overrepresentation of Black race and an underrepresentation of White and Asian races overall Obstetrics and in most subcategories. We observed an overrepresentation of Black race and an underrepresentation of Asian race in Gynecology overall and in most subcategories. White race representation was similar to the general population on average, but with wide variation across studies especially among the subcategories. Hispanic ethnicity was overall underrepresented. Conclusions: RCTs in the field of Obstetrics and Gynecology conducted in the U.S. deviate from the general population with regard to racial and ethnic distributions. Funding: NC,YW, CP, JG and SL received stipend from University of Chicago Metcalf summer internship program and Odyssey and Empower summer program. Keywords: U.S. Randomized Controlled Trials, Racial and Ethnic Backgrounds, Obstetrics and Gynecology
\end{abstract}

\section{Hosted file}

Main File RCT for BJOG.pdf available at https://authorea.com/users/396801/articles/509880racial-and-ethnic-backgrounds-of-u-s-randomized-controlled-trials-in-obstetrics-andgynecology-and-comparison-to-u-s-general-population-a-retrospective-review

\section{Hosted file}

Figures for BJOG.pdf available at https://authorea.com/users/396801/articles/509880-racialand-ethnic-backgrounds-of-u-s-randomized-controlled-trials-in-obstetrics-and-gynecologyand-comparison-to-u-s-general-population-a-retrospective-review 